\title{
Investigation of the Characteristic Properties of Glacial Acetic Acid-Catalyzed Carbon Xerogels and Their Electrochemical Performance for Use as Electrode Materials in Electrical Double-Layer Capacitors
}

\author{
Nguyen Khanh Nguyen Quach, ${ }^{1}$ Wein-Duo Yang, ${ }^{1}$ Zen-Ja Chung, \\ Hoai Lam Tran, ${ }^{3}$ and Rui Liu ${ }^{4}$ \\ ${ }^{1}$ Department of Chemical and Materials Engineering, National Kaohsiung University of Applied Sciences, 415 Chien-Kung Road, \\ Kaohsiung 807, Taiwan \\ ${ }^{2}$ Chemical Engineering Division, Institute of Nuclear Energy Research, Lungtan, Taoyuan 325, Taiwan \\ ${ }^{3}$ Faculty of Chemistry, Dong Thap University, Dong Thap 93000, Vietnam \\ ${ }^{4}$ School of Science, Harbin University of Commerce, Harbin 150076, China
}

Correspondence should be addressed to Wein-Duo Yang; ywd@kuas.edu.tw

Received 6 March 2017; Revised 27 April 2017; Accepted 30 April 2017; Published 21 May 2017

Academic Editor: Daniel Guay

Copyright (C) 2017 Nguyen Khanh Nguyen Quach et al. This is an open access article distributed under the Creative Commons Attribution License, which permits unrestricted use, distribution, and reproduction in any medium, provided the original work is properly cited.

\begin{abstract}
Glacial acetic acid was used as a catalyst in the preparation process of carbon xerogels from the condensation of resorcinol and formaldehyde for shortening significantly the gelation time. The effect of the resorcinol/catalyst ratio over a large range of 2 to 500 , the solvent exchange manner with acetone, and the pyrolysis temperature of 700 to $1000^{\circ} \mathrm{C}$ on the characteristic properties of the carbon xerogels were investigated. A resorcinol/catalyst ratio of 2 and a pyrolysis temperature at $800^{\circ} \mathrm{C}$ were found to be the optimal condition for the preparation of carbon xerogels with a well-balanced porosity between micro- and mesopores, high surface area $\left(577.62 \mathrm{~m}^{2} \mathrm{~g}^{-1}\right)$, and large pore volume $\left(0.97 \mathrm{~cm}^{3} \mathrm{~g}^{-1}\right)$, which are appropriate for use as electrode materials in an electrical double-layer capacitor. The carbon xerogel electrodes that were prepared under these optimal conditions exhibited a good electrochemical performance with the highest specific capacitance of $169 \mathrm{Fg}^{-1}$ in $6 \mathrm{M} \mathrm{KOH}$ electrolyte at a scan rate of $5 \mathrm{mVs}^{-1}$ from cyclic voltammetry.
\end{abstract}

\section{Introduction}

In the early 1950s, supercapacitors with porous carbon electrodes [1] began to be investigated but they have been just developed powerfully in recent years. Thus, electrode materials have also received much research attention by scientists seeking to find new materials with the most appropriate structural properties in order to improve the electrochemical performance of supercapacitors so that they have the power density of conventional capacitors and the energy density of electrochemical batteries.

Carbon aerogels were found first by Pekala [2] like a promising material with excellent properties such as low density, high electrical conductivity, high surface area, and large pore volume. These properties are continuously being studied and enhanced by improving the structure of the material. Thus, the detailed investigations on the factors affecting the structure of the material (such as the precursor ratio, catalyst, and pyrolysis temperature) are necessary, so that the material has the most appropriate structural properties to be used as an electrode material in the electrical doublelayer capacitor. Moreover, the impurity of the materials also significantly affects their electrochemical performance due to increasing the inner resistance of the electrode, so the organic acid-catalysts are gradually replacing the alkalinecatalysts (e.g., $\mathrm{NaOH}$ [3], $\mathrm{NaHCO}_{3}$ [4], and $\mathrm{Na}_{2} \mathrm{CO}_{3}$ [5-8]) 
in the preparation of carbon xerogel. Besides, the preparation procedure is also more and more simplified; the simple drying in ambient conditions is suggested to replace more complicated methods in vacuum condition [2, 9-12] before to reduce the cost of products.

In this work, we investigated the effects of the resorcinol/catalyst ratio, the manner of solvent exchange by acetone, and the pyrolysis temperature on the characteristic properties of carbon xerogels, which were prepared from the condensation of resorcinol and formaldehyde, to determine the optimal conditions to prepare carbon xerogels for use as an electrode material in the electrical doublelayer capacitor. Glacial acetic acid was used as a catalyst to restrict the impurity in the carbon xerogels. In addition, the electrochemical performance of the carbon xerogels was investigated to determine the optimal conditions to prepare carbon xerogels for the electrode material in the electrical double-layer capacitor.

\section{Experimental Methods}

2.1. Carbon Xerogel Synthesis Method. Organic xerogel was prepared from the condensation of resorcinol and formaldehyde with a molar ratio of $1: 2$. After the initial surveys, a mass ratio $M$ of 60 was selected and glacial acetic acid was added as the catalyst with molar ratios of resorcinol and catalyst ( $\mathrm{RC}$ ratio) over a large range of 2 to 500 . To exclude the solvent effect of catalyst no sample with an RC ratio less than 1 was prepared. These mixtures were stirred for 30 minutes, transferred into a glass vial, and subsequently placed in an oven at $80^{\circ} \mathrm{C}$ for 3 days to obtain a gel. The resulting gel was immersed in acetone for 2 days to remove residual precursors and was subsequently dried for 1 day under ambient pressure to generate the organic xerogel. The acetone exchange process was performed via two methods with identical acetonechanging times: first (S1), fresh acetone was supplied every 6 hours; second (S2), acetone was changed after every 3 hours during the 1st day. Carbon xerogel was prepared by carbonizing the organic gel at different temperatures of 700 to $1000^{\circ} \mathrm{C}$ in nitrogen for $3 \mathrm{~h}$ with a tube furnace.

Carbon xerogel samples were denoted as RCS $n-T$, where $\mathrm{S} n$ is the method of the acetone exchange process $(\mathrm{S} 1, \mathrm{~S} 2)$ and $T$ is the pyrolysis temperature $\left(700-1000^{\circ} \mathrm{C}\right)$.

2.2. Characterization. A Perkin-Elmer thermogravimetric analyzer (TGA) was used to determine the weight loss behavior and thermal effect of the organic xerogels during carbonization in nitrogen and carbon xerogels in air. Scanning electron microscopy was performed with a JEOL microscope (model JSM $6330 \mathrm{TF}$ ). The BET surface area, BJH mesopore area, t-Plot micropore area, and $\mathrm{N}_{2}$ adsorptiondesorption isotherm were obtained using a Micrometrics ASAP 2020 instrument.

\subsection{Electrochemical Properties}

Fabrication Electrodes of RCSn-T. Each carbon xerogel sample was mixed with polytetrafluoroethylene as a binder and black carbon as a conductive additive with a weight ratio of $8: 1: 1$ in 2-propanol. After the slurry was sonicated for 30 minutes to generate a homogeneous mixture, the resultant slurry was coated onto graphite paper as a current collector.

The electrochemical properties were investigated using a conventional three-electrode cell system in $6 \mathrm{M} \mathrm{KOH}$ electrolyte with cyclic voltammetry and galvanostatic charge/ discharge method. The cyclic voltammetry measurement was carried out at a scan rate of 5 to $100 \mathrm{mV} \mathrm{s}^{-1}$ within the voltage range of -1.0 to $0 \mathrm{~V}$. The galvanostatic charge/discharge measurement was performed at constant current densities of 1 and $5 \mathrm{~A} \mathrm{~g}^{-1}$ within the same voltage range using for cyclic voltammetry measurement.

\section{Result and Discussion}

3.1. Characterization of Material. All organic xerogels, which were synthesized from condensation of resorcinol and formaldehyde with an RC ratio of 2 to 500, showed monolithic and homogeneous samples with low densities of 0.37 to $0.45 \mathrm{gcm}^{-3}$. The utilization of glacial acetic acid as the catalyst contributes to shortening significantly the gelation time in few hours due to the growth mechanism under acid catalysis, which is based on acceleration of the reaction by increasing the electrophilicity of formaldehyde and eventually polymerization leads to formation of particles. The particle size depends on the $\mathrm{RC}$ ratios, which can be observed in Figure 1 with SEM images of carbon xerogels in various $\mathrm{RC}$ ratios. Increasing the RC ratios decreases the formation of hydroxymethylated resorcinol and thus the generated clusters are weakly branched, the cross-linked clusters are more stable, and the nucleation regime is longer, resulting in the generation of larger particles with less interconnected particles $[13,14]$. So carbon xerogel prepared with the higher RC ratio exhibits the interconnected particles morphology with larger particles compared to the others, which were prepared with lower RC ratios.

The porosity of the carbon xerogel samples that were prepared with an RC ratio of 2 to 500 was probed using nitrogen sorption analysis. The nitrogen adsorption-desorption isotherms and pore size distribution of these samples are shown in Figures 2 and 3. The BET surface area, micropore surface area, pore volume, and pore size are listed in Table 1.

In the carbon xerogels RCS1-900 series, the carbon xerogels with $\mathrm{RC}$ ratios above 32 showed type I isotherms and exhibited essentially no hysteresis loop (in Figure 2), indicating that these samples have a mainly microporous structure, which can be observed in the pore size distribution (shown in Figure 3). When the RC ratios were low (2 and 8), the isotherms were type IV with an $\mathrm{H} 2$ type hysteresis loop, which is characteristic of well-developed porous structures. It is noticed that there is clearly a change in the nitrogen adsorption-desorption isotherms and the hysteresis loop of 2S1-900 sample compared to the other carbon xerogel samples with lower RC ratios as a result of the best development in the porous carbon structure, particularly, the generation of large mesopore amount in its structure with a much higher mesopore volume compared with that of the other 


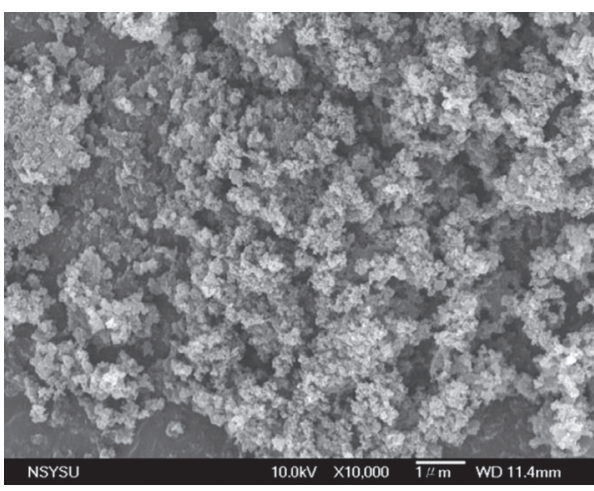

(a)

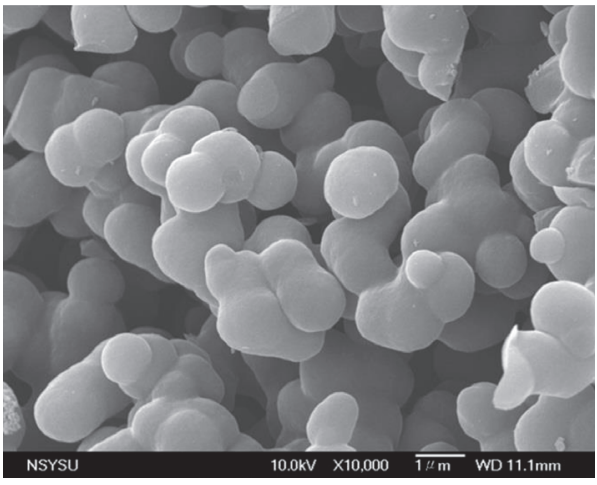

(c)

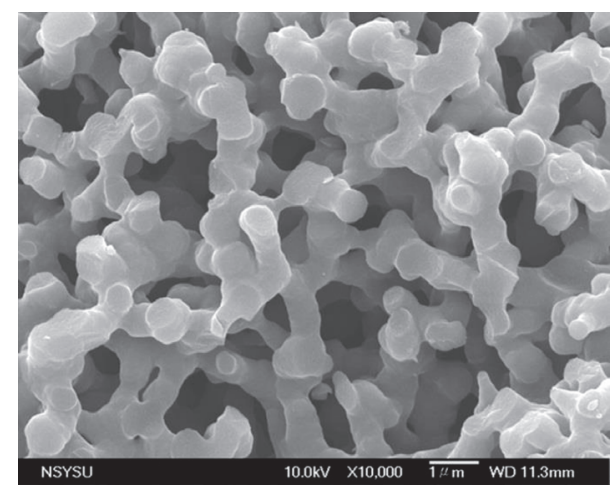

(b)

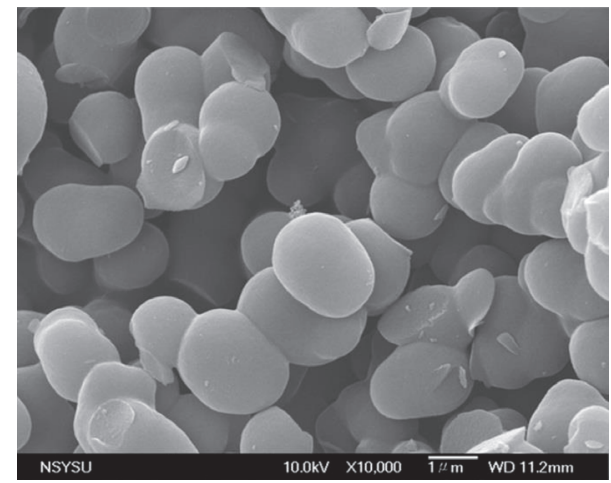

(d)

FIGURE 1: SEM images of carbon xerogels synthesized with RC ratio of 2S1-900 (a), 8S1-900 (b), 32S1-900 (c), and 500 S1-900 (d).

TABLE 1: Physical properties of carbon xerogels prepared with various RC ratios.

\begin{tabular}{|c|c|c|c|c|c|c|}
\hline Number & Name & $\begin{array}{c}S_{\mathrm{tot}} \\
\mathrm{m}^{2} \mathrm{~g}^{-1}\end{array}$ & $\begin{array}{l}S_{\text {micro }} \\
\mathrm{m}^{2} \mathrm{~g}^{-1} \\
\end{array}$ & $\begin{array}{c}V_{\text {tot }} \\
\mathrm{cm}^{3} \mathrm{~g}^{-1}\end{array}$ & $\begin{array}{c}\text { Pore size } \\
\mathrm{nm}\end{array}$ & $\begin{array}{c}\text { Density } \\
\mathrm{gcm}^{-3}\end{array}$ \\
\hline \multicolumn{7}{|c|}{ Carbon xerogel with $R C$ in large range from 2 to 500} \\
\hline 1 & 2S1-900 & 499.50 & 352.87 & 0.69 & 5.53 & 0.42 \\
\hline 2 & $8 S 1-900$ & 483.90 & 420.71 & 0.27 & 2.20 & 0.40 \\
\hline 3 & $32 S 1-900$ & 472.77 & 428.93 & 0.22 & 1.90 & 0.38 \\
\hline 4 & $125 S 1-900$ & 463.17 & 416.91 & 0.25 & 2.12 & 0.38 \\
\hline 5 & 500 S1-900 & 448.47 & 403.06 & 0.24 & 2.13 & 0.37 \\
\hline \multicolumn{7}{|c|}{ Effect of pyrolysis temperature on $2 S 2-T$} \\
\hline 1 & $2 S 2-700$ & 529.28 & 345.12 & 0.83 & 6.26 & 0.45 \\
\hline 2 & $2 S 2-800$ & 577.62 & 389.83 & 0.97 & 6.72 & 0.44 \\
\hline 3 & $2 S 2-900$ & 527.32 & 360.98 & 1.0 & 7.56 & 0.43 \\
\hline 4 & $2 S 2-1000$ & 508.73 & 345.82 & 0.93 & 7.27 & 0.43 \\
\hline
\end{tabular}

carbon xerogels (shown in Figure 3). This result is logical with the SEM image of 2S1-900 sample with a densest morphology of the interconnected small particle network structure. Consequently, 2S1-900 sample had the highest BET surface area and the largest pore volume compared to the other carbon xerogels in RCS1-900 series (Table 1), whereas there is no large change in the pore size and pore volume of the carbon xerogels that were prepared with $\mathrm{RC}$ ratios higher 32. This result may be explained by the relatively large acidity constant of glacial acetic acid $\left(\mathrm{p} K_{a}=4.76[15]\right)$.
Furthermore, the effect of a solvent exchange process by acetone on the characteristic properties of carbon xerogels was also surveyed to determine the optimal manner. By comparing the characteristic properties of two samples prepared in the same preparation condition, but with two different manners of solvent exchange by acetone: 2S1-900 sample, which was prepared by changing the fresh acetone every 6 hours over 2 days, and 2S2-900 sample, which was prepared by changing the fresh acetone after 3 hours on the 1st day, the two samples show the approximate micropore areas but 


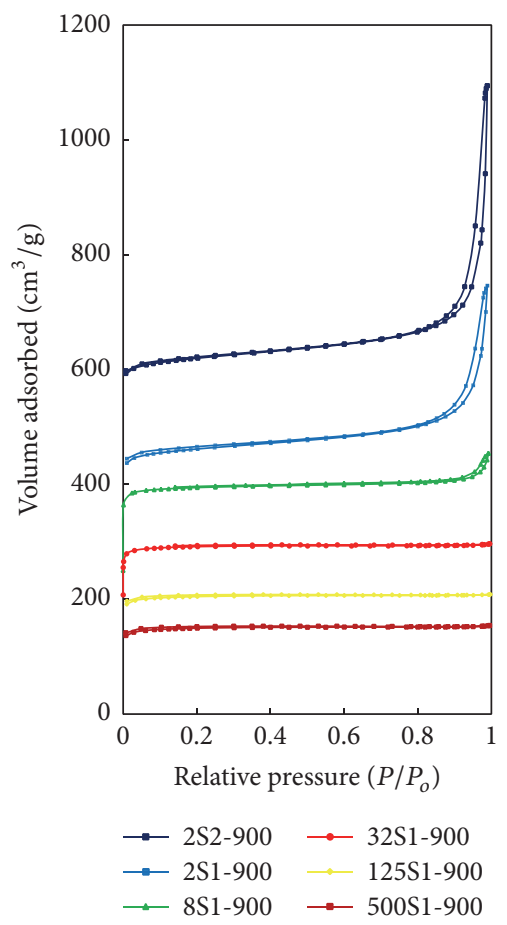

FIGURE 2: Nitrogen adsorption-desorption isotherms of carbon xerogels prepared with various RC ratios.

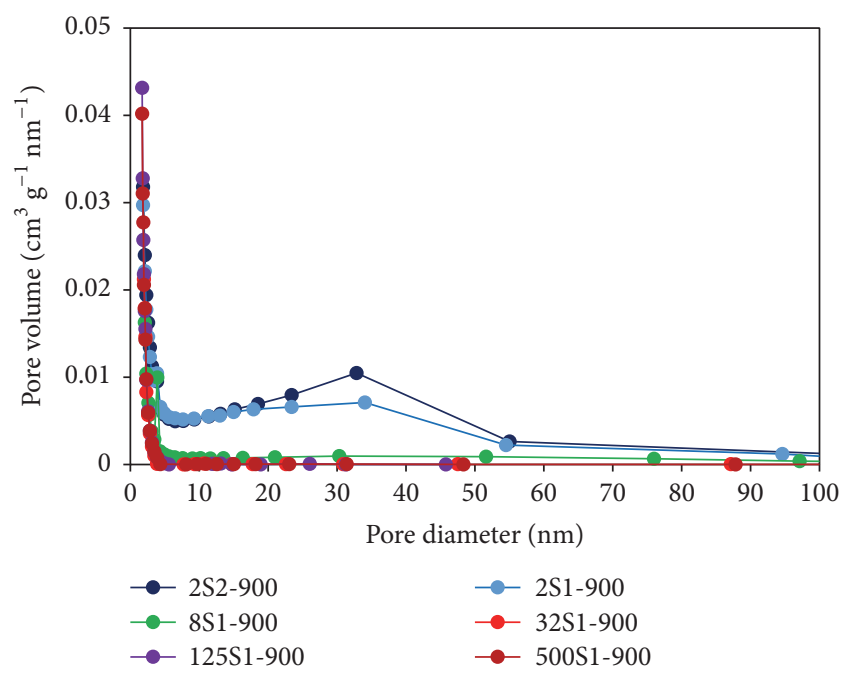

FIGURE 3: Pore size distribution of carbon xerogels prepared with various RC ratios.

the mesopore area of 2S2-900 sample is rather higher than that of 2S1-900 sample, leading to increase in its BET surface area, pore volume, and average pore size significantly. More development in porous structure of 2S2-900 sample can be observed more clearly by its nitrogen adsorption-desorption isotherms and pore size distribution compared to that of 2S1900 sample in Figures 2 and 3. It indicates that the continuous solvent exchange process by fresh acetone immediately after finishing the gelation process plays an important role in maintaining mesopores due to reducing the surface tensions upon drying in ambient conditions; it leads to restriction of the collapse of the weak gel network [16, 17], which on the carbonization slowly generates carbon porosity. From the above investigated results, the $\mathrm{RC}$ ratio of 2 and acetone exchange after every 3 hours during the first day were selected for preparation conditions of carbon xerogels in the next investigation.

The effect of pyrolysis temperature on the characteristic of carbon xerogels was investigated in range of $700-1000^{\circ} \mathrm{C}$; carbon xerogel pyrolyzed at $800^{\circ} \mathrm{C}$ has the highest BET surface area of $577.62 \mathrm{~m}^{2} \mathrm{~g}^{-1}$ (Table 1). The change in the structural properties of carbon xerogels with increasing pyrolysis temperature ranging of $700-1000^{\circ} \mathrm{C}$ can be interpreted from the density change and TGA curve shown in Figure 4(a). From TGA curve, there is a great weight loss at temperature lower $800^{\circ} \mathrm{C}$ as a result of breaking the $\mathrm{C}-\mathrm{O}$ and $\mathrm{C}-\mathrm{H}$ bonds to $\mathrm{C}-\mathrm{C}$ bond formation, resulting in the increase of pore volume with pyrolysis temperature. Above $800^{\circ} \mathrm{C}$ a little weight loss was shown, but densities of carbon xerogels still decrease to $900^{\circ} \mathrm{C}$. Meanwhile, the shrinkage of some pores begins to occur under the high temperature effect. These behaviors make the pore volume and average pore size reduce with increasing pyrolysis temperature up to $1000^{\circ} \mathrm{C}$. Consequently, carbon xerogel pyrolyzed at $800^{\circ} \mathrm{C}$ has the highest BET surface area.

Besides, the thermal effect of carbon xerogels pyrolyzed at different temperatures in air was also analyzed by TGA (Figure $4(\mathrm{~b})$ ). The weight loss below $100^{\circ} \mathrm{C}$ is attributed to the evaporation of the adsorbed water. The carbon xerogels pyrolyzed at temperatures above $800^{\circ} \mathrm{C}$ had high stability up to $460^{\circ} \mathrm{C}$, and their oxidation occurred in the temperature range $460-640^{\circ} \mathrm{C}$, in which $2 \mathrm{~S} 2-1000$ sample had the highest stability with the highest burn off temperature of $640^{\circ} \mathrm{C}$. This high thermal stability of the carbon xerogel samples is attributed to the generation of the more crystalline network structures at high pyrolysis temperatures, which can be observed more clearly by the XRD patterns of the carbon xerogel samples displayed in Figure 5. All carbon xerogel samples show two diffraction peaks of (002) and (101) corresponding to the graphitic phase of carbon [18]. However, the two peak intensities of (002) and (101) of carbon xerogel samples pyrolyzed at temperature above $800^{\circ} \mathrm{C}$ were higher than those of the carbon xerogel sample pyrolyzed at temperature $700^{\circ} \mathrm{C}$, indicating the more crystalline network structures of carbon xerogel samples pyrolyzed at temperature above $800^{\circ} \mathrm{C}$ compared to the carbon xerogel sample pyrolyzed at temperature $700^{\circ} \mathrm{C}$.

3.2. Electrochemical Properties. The RC ratios, manner of solvent exchange by acetone, and pyrolysis temperature affect not only the characteristic properties, but also the electrochemical performance of carbon xerogel electrodes. In order to evaluate these effects, the electrochemical performance of carbon xerogel electrodes was measured by cyclic voltammetry and galvanostatic charge/discharge using the conventional three-electrode cell system, where a platinum plate and $\mathrm{AgCl} / \mathrm{Ag}$ electrode were used as the counter electrode and reference electrode, respectively. A $6 \mathrm{M} \mathrm{KOH}$ 


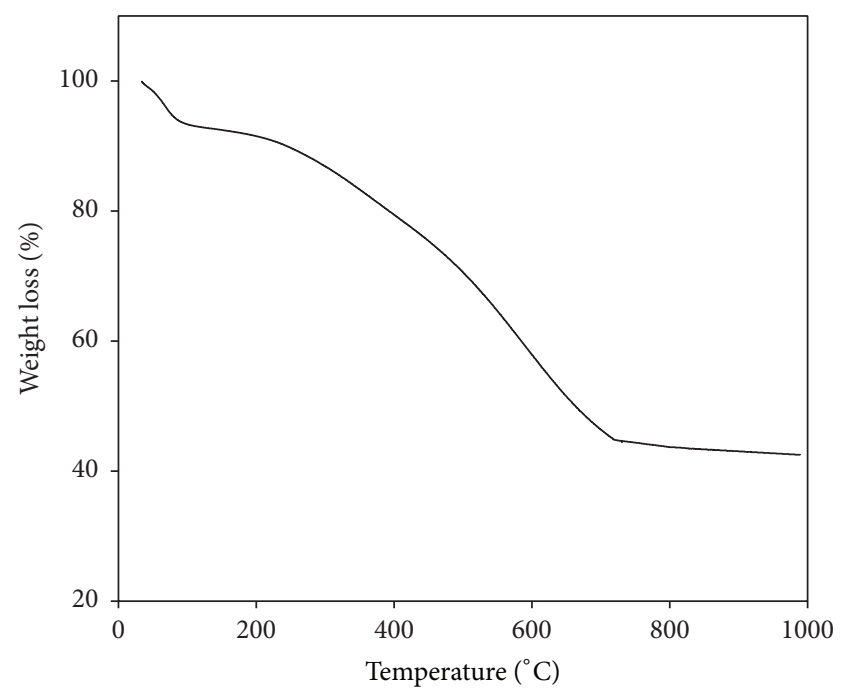

(a)

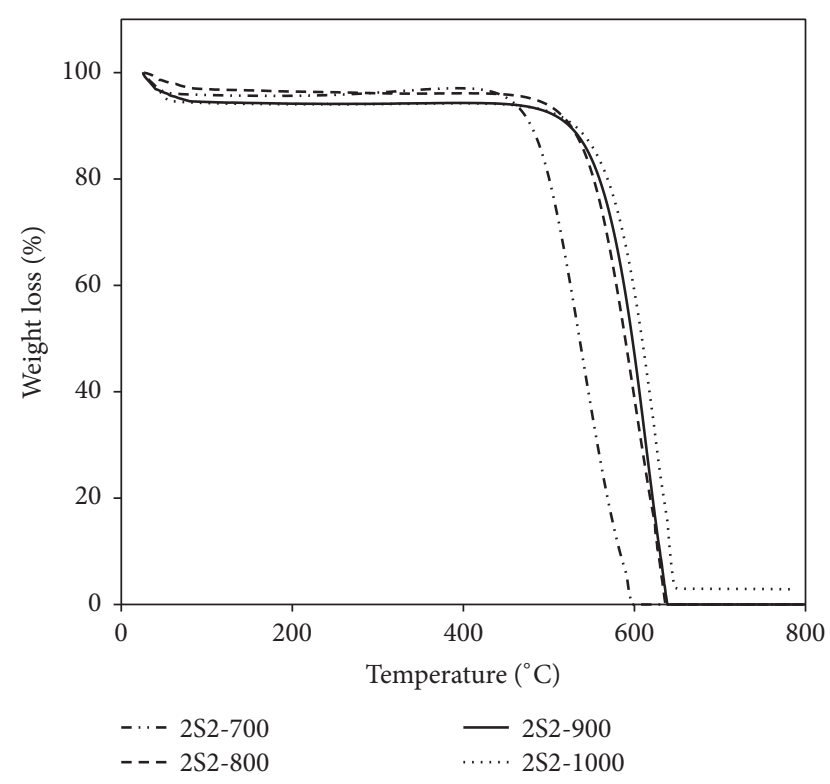

(b)

FIGURE 4: Thermal gravimetric curves of organic xerogel (a) and carbon xerogels (b) pyrolyzed at different temperatures.

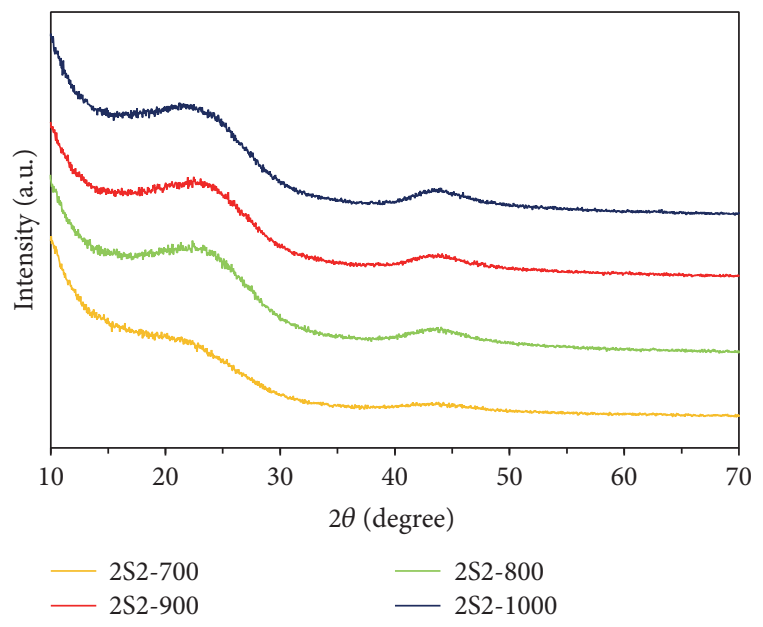

FIGURE 5: XRD patterns of carbon xerogel samples pyrolyzed at different temperatures.

solution was used as the electrolyte. For the effect of RC ratio, the electrochemical properties were investigated with carbon xerogel electrodes in RCS1-900 series. The cyclic voltammograms of all RCS1-900 electrodes at a scan rate of $10 \mathrm{mVs}^{-1}$ are shown in Figure 6. The calculated specific capacitances are listed in Table 2 with the highest specific capacitance value of 2S1-900 electrode.

The improvement in electrochemical performance of carbon xerogel electrodes can be explained by the difference in their structural properties such as high surface area, large pore volume. In addition, pore size in range 3-13 nm [19] as well as the generation of a considerable mesopore fraction in carbon structure results in very high specific

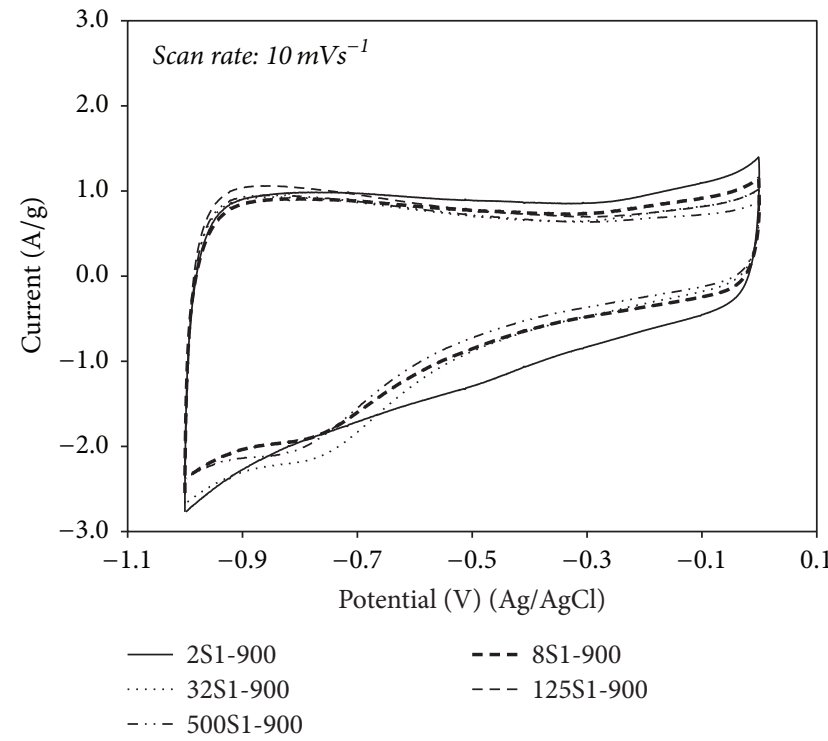

Figure 6: Cyclic voltammograms of RCS1-900 electrodes at a scan rate of $10 \mathrm{mVs}^{-1}$.

capacitance values and also in a stable electrochemical performance. Thus, 2S1-900 electrode achieved the highest specific capacitance of $112 \mathrm{Fg}^{-1}$ and the most stable electrochemical performance compared to the other electrodes in RCS1-900 series. The cyclic voltammogram of 2S1-900 electrode had more nearly rectangular shape with a lower current decay at high voltage compared to the other electrodes, which have mainly micropores, resulting in the increase of inner resistance. Moreover, increasing the RC ratio reduces the electrical conductivity of carbon xerogels [20]. Those make the cyclic voltammograms more distorted at high voltage and 
TABLE 2: Specific capacitance obtained from cyclic voltammetry of carbon xerogel electrodes prepared with various RC ratios at a scan rate of $10 \mathrm{mVs}^{-1}$.

\begin{tabular}{lccccc}
\hline RC ratio & 2 S1-900 & 8 S1-900 & 32 S1-900 & 125 S1-900 & 500 S1-900 \\
\hline Specific capacitance, $\mathrm{Fg}^{-1}$ & 112 & 100 & 96 & 92 & 88 \\
\hline
\end{tabular}

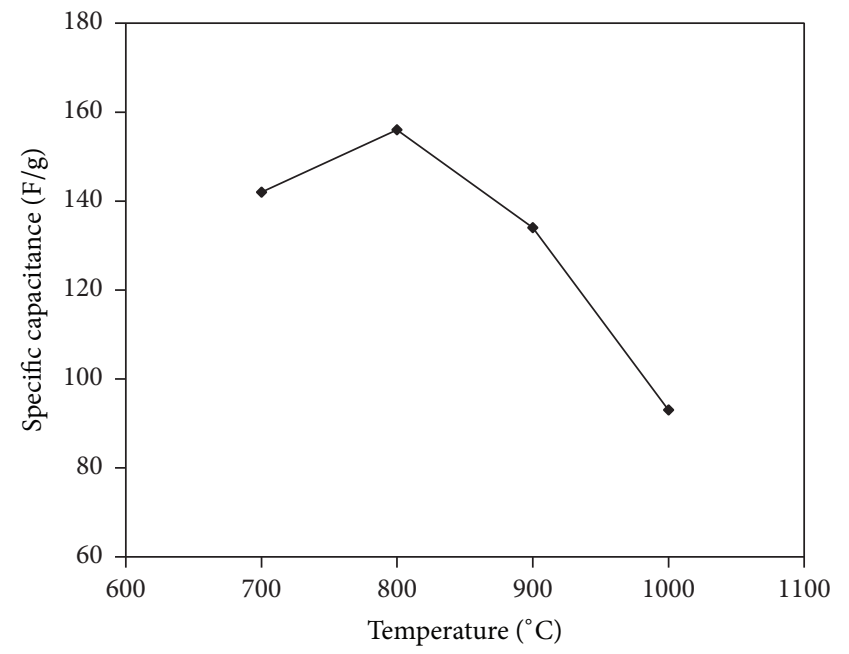

Figure 7: Specific capacitances of 2S2-T electrodes determined by cyclic voltammetry at a scan rate of $10 \mathrm{mVs}^{-1}$.

the decline of specific capacitance values with increasing RC ratios.

By comparison, the electrochemical performance of the 2S1-900 electrode and 2S2-900 electrode may further affirm the important role of maintaining of mesopores by the continuous solvent exchange by fresh acetone in the carbon xerogel preparation via drying in ambient conditions. The mesopores make the electrolyte ion adsorption easier; subsequently, these electrolyte ions were transferred to the micropores, which improve the electrochemical performance by maximizing the charge accumulation. 2S2-900 sample with the more preeminent structural properties such as high surface area, large pore volume, a well-balanced porosity, and thus 2S2-900 electrode has a higher specific capacitance value $\left(134 \mathrm{Fg}^{-1}\right)$ than that of 2 S1-900 electrode $\left(112 \mathrm{Fg}^{-1}\right)$.

Figure 7 shows the effect of pyrolysis temperature on the specific capacitance of carbon xerogel electrodes determined by cyclic voltammetry at a scan rate of $10 \mathrm{mVs}^{-1}$. These results are entirely consistent with the BET results (Table 1). All carbon xerogel electrodes in this $2 \mathrm{~S} 2-T$ series retained the general electrochemical performance of carbon material and the carbon xerogel 2S2-800 sample with the highest surface area of $577.62 \mathrm{~m}^{2} \mathrm{~g}^{-1}$ and large pore volume of $0.97 \mathrm{~cm}^{3} \mathrm{~g}^{-1}$ reaches a maximum specific capacitance of $156 \mathrm{Fg}^{-1}$ at scan rate of $10 \mathrm{mVs}^{-1}$. From the obtained results, an RC ratio of 2 , the manner of acetone exchange after every 3 hours during the first day, and pyrolysis temperature at $800^{\circ} \mathrm{C}$ are also the best optimal conditions to prepare carbon xerogels for electrochemical applications, or 2S2-800 sample is the best sample found from condensation of resorcinol and formaldehyde using glacial acetic acid as the catalyst for
TABLE 3: Specific capacitance obtained from cyclic voltammetry of 2S2-800 electrode at various scan rates.

\begin{tabular}{lc}
\hline Scan rate, $\mathrm{mVs}^{-1}$ & Specific capacitance, $\mathrm{Fg}^{-1}$ \\
\hline 5 & 169 \\
10 & 156 \\
30 & 138 \\
50 & 128 \\
100 & 109 \\
\hline
\end{tabular}

electrode material in electric double-layer capacitor. So, a more detail investigation in electrochemical performance of 2S2-800 electrode is necessary.

The cyclic voltammograms of 2S2-800 electrode at various scan rates of 10 to $100 \mathrm{mVs}^{-1}$ are exhibited in Figure 8. Its calculated specific capacitances at various scan rates of 5 to $100 \mathrm{mVs}^{-1}$ are listed in Table 3. In Figure 8, the cyclic voltammograms of 2S2-800 electrode at low scan rate showed a similar rectangular shape; it indicates that carbon xerogel electrodes prepared from condensation of resorcinol and formaldehyde using glacial acetic acid as the catalyst have a stable electrochemical performance in $6 \mathrm{M} \mathrm{KOH}$ electrolyte. At higher scan rates the cyclic voltammograms began to be distorted due to increasing the obstructive capacity of the carbon network structure against electrolyte ion diffusion, leading to reduced ion transfer rate in the electrolyte at high scan rate. Consequently, the calculated specific capacitance of 2S2-800 electrode decreases with increasing scan rate from cyclic voltammetry.

The obtained electrochemical performance of 2S2-800 electrode from charge/discharge galvanostatic at various current densities, listed in Table 4, agrees entirely with the results of cyclic voltammetry measurements. The charge/discharge curve of 2S2-800 electrode at current densities $1 \mathrm{Ag}^{-1}$ and $5 \mathrm{Ag}^{-1}$ (shown in Figure 9) exhibited a triangular shape and the calculated specific capacitance of 2S2-800 electrode decreases with increasing current density from charge/discharge galvanostatic. 2S2-800 electrode had the high specific capacitance of $159 \mathrm{Fg}^{-1}$ and energy density of $5.52 \mathrm{Whkg}^{-1}$ at a current density of $1 \mathrm{Ag}^{-1}$.

The cycle life of carbon xerogel 2S2-800 sample is also illustrated in Figure 10. The capacitance data is collected using the charge/discharge galvanostatic at current density $1 \mathrm{Ag}^{-1}$ after a certain initial number of charging/discharging cycles. The 2S2-800 capacitance retains a rather stable cyclic behavior after 1000 cycles; it indicates that carbon xerogel electrode has good charge/discharge performances in $\mathrm{KOH}$ electrolyte.

Besides, one carbon aerogel sample (CA) with a mainly microporous structure, which has higher BET surface area of $660.55 \mathrm{~m}^{2} \mathrm{~g}^{-1}$ with micropore surface area of $593.91 \mathrm{~m}^{2} \mathrm{~g}^{-1}$ 

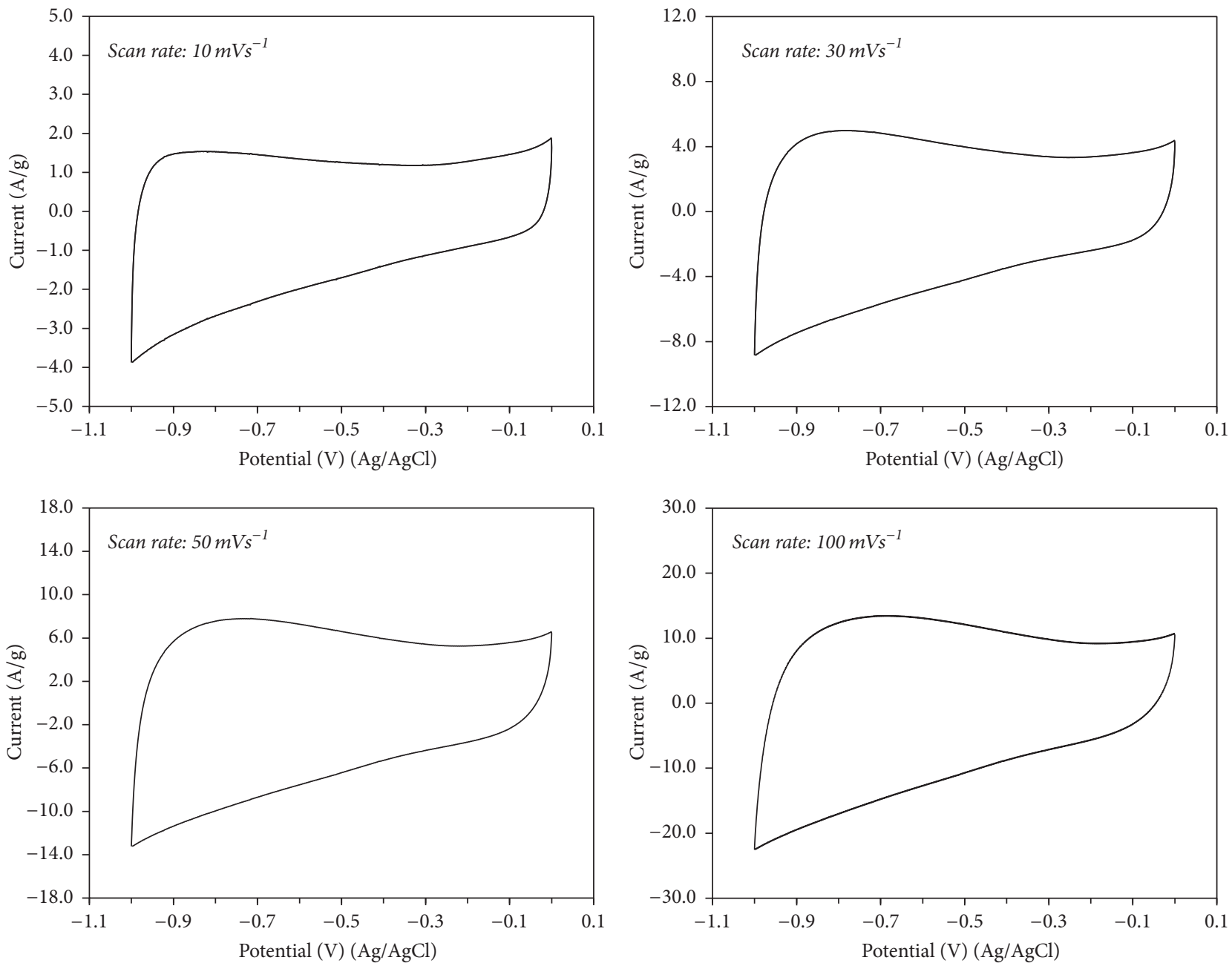

FIGURE 8: Cyclic voltammograms of 2S2-800 electrode at various scan rates $\left(10,30,50\right.$, and $\left.100 \mathrm{mVs}^{-1}\right)$.
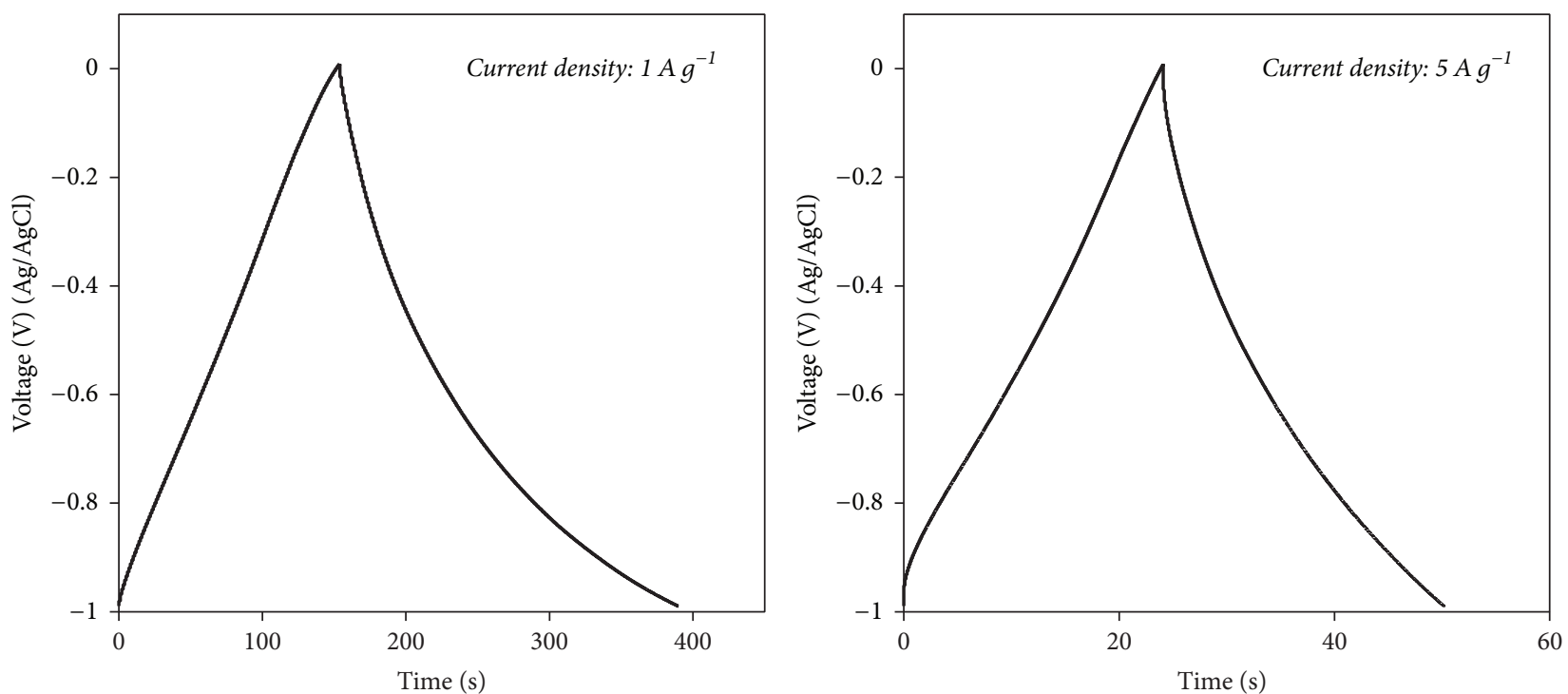

FIGURE 9: Charge/discharge curve of the 2S2-800 electrode at current densities of $1 \mathrm{Ag}^{-1}$ and $5 \mathrm{Ag}^{-1}$. 
TABLE 4: Specific capacitance obtained from charge/discharge galvanostatic of 2S2-800 electrode at various current densities.

\begin{tabular}{lccc}
\hline Current density, $\mathrm{Ag}^{-1}$ & Specific capacitance, $\mathrm{Fg}^{-1}$ & Energy density, $\mathrm{Whkg}^{-1}$ & $\mathrm{Power} \mathrm{density,} \mathrm{Wkg}^{-1}$ \\
\hline 1 & 159 & 5.52 & 124.98 \\
3 & 135 & 4.69 & 375.20 \\
5 & 119 & 4.13 & 624.70 \\
\hline
\end{tabular}

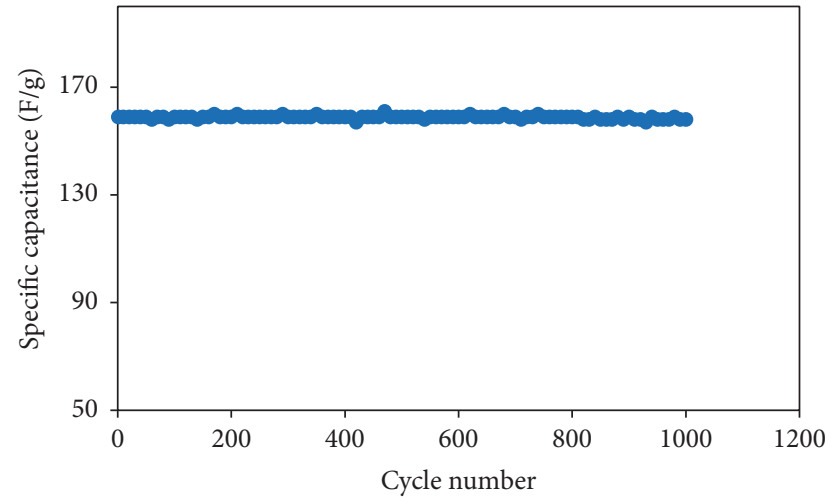

Figure 10: Galvanostatic cycling tests at current densities $1 \mathrm{Ag}^{-1}$ between $-1 \mathrm{~V}$ and $0 \mathrm{~V}$.

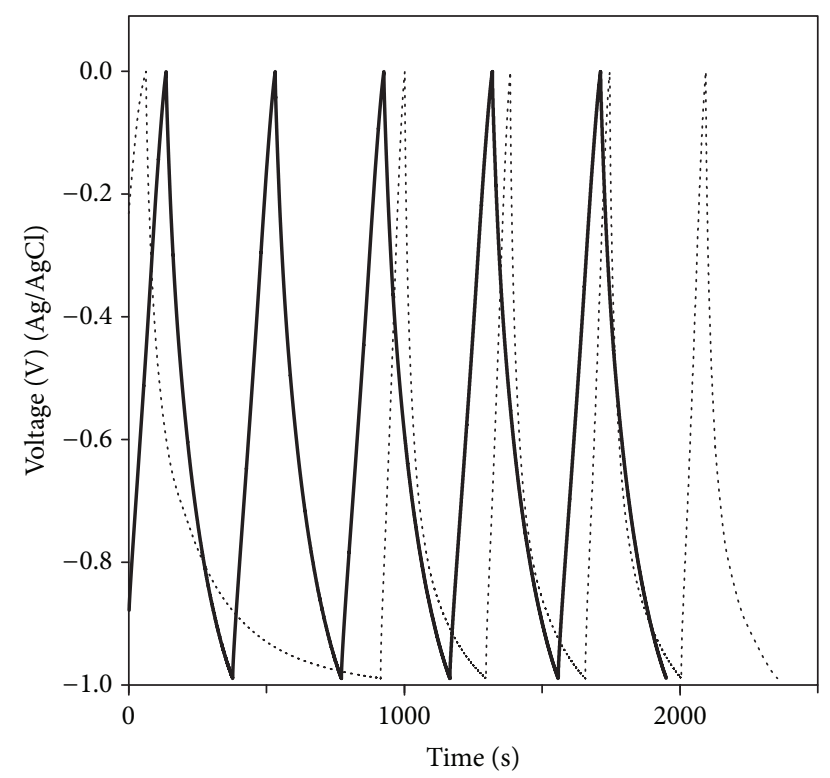

FIGURE 11: Charge/discharge curve of the 2S2-800 electrode (solid line) and carbon aerogel electrode with a mainly microporous structure (dot line) at current densities of $1 \mathrm{Ag}^{-1}$.

but smaller pore volume of $0.35 \mathrm{~cm}^{3} \mathrm{~g}^{-1}$ and pore size of $2.13 \mathrm{~nm}$ than $2 \mathrm{~S} 2-800$ sample, was also prepared according to [9] for comparing the electrochemical performance. 2S2800 electrode showed a specific capacitance value, which can be compared with that of CA at a current density of $1 \mathrm{Ag}^{-1}$; particularly, it reduced significantly the charge/discharge time of the first cycles to reach the stable state (in Figure 11) due to the decrease of the inner resistance that contributes to improving the application performance of the material. This result also indicates that not only the specific surface area but also pore volume, pore size, and well-balanced porosity between the micro- and mesopores also play an important role in improving the electrochemical performance of the materials. And the structural properties of 2S2-800 sample are preeminent for use as electrode material.

\section{Conclusions}

The acid-catalyzed carbon xerogel structural properties were investigated in large range from mainly microporous to micro/mesoporous structure which led to the different application abilities of the materials, in which carbon xerogel prepared with a resorcinol/catalyst ratio of 2 and a pyrolysis temperature of $800^{\circ} \mathrm{C}$ were found to have the most appropriate structure to be used as an electrode material with high surface area, large pore volume, and especially a wellbalanced porosity between the micro- and mesopores, which improve the electrochemical performance of materials. The carbon xerogel electrode showed an excellent electrochemical performance with a highest specific capacitance of $169 \mathrm{Fg}^{-1}$ at a scan rate of $5 \mathrm{mVs}^{-1}$ based on the cyclic voltammetry. Besides, the utilization of glacial acetic acid as the catalyst significantly shortened the gelation time in the preparation process of carbon xerogels from the condensation of resorcinol and formaldehyde that contributes to reducing the cost of products.

\section{Conflicts of Interest}

The authors declare that they have no direct financial relation with the commercial identities mentioned in this paper that might lead to conflicts of interest for any of them.

\section{Acknowledgments}

The authors would like to thank the Ministry of Science and Technology of Taiwan for its financial support of this work (Grant no. MOST 103-2221-E-151-055).

\section{References}

[1] H. I. Becker, "Low voltage electrolytic capacitor," US patent 2800616, 1957.

[2] R. W. Pekala, "Organic aerogels from the polycondensation of resorcinol with formaldehyde," Journal of Materials Science, vol. 24, no. 9, pp. 3221-3227, 1989.

[3] G. Qin and S. Guo, "Preparation of RF organic aerogels and carbon aerogels by alcoholic sol-gel process," Carbon, vol. 39, no. 12, pp. 1935-1937, 2001. 
[4] B. Fang, Y.-Z. Wei, K. Maruyama, and M. Kumagai, "High capacity supercapacitors based on modified activated carbon aerogel," Journal of Applied Electrochemistry, vol. 35, no. 3, pp. 229-233, 2005.

[5] Y. J. Lee, H. W. Park, G.-P. Kim, J. Yi, and I. K. Song, "Supercapacitive electrochemical performance of graphene-containing carbon aerogel prepared using polyethyleneimine-modified graphene oxide," Current Applied Physics, vol. 13, no. 5, pp. 945949, 2013.

[6] A. Halama, B. Szubzda, and G. Pasciak, "Carbon aerogels as electrode material for electrical double layer supercapacitors-synthesis and properties," Electrochimica Acta, vol. 55, no. 25, pp. 7501-7505, 2010.

[7] E. Gallegos-Suárez, A. F. Pérez-Cadenas, F. J. MaldonadoHódar, and F. Carrasco-Marín, "On the micro- and mesoporosity of carbon aerogels and xerogels. The role of the drying conditions during the synthesis processes," Chemical Engineering Journal, vol. 181-182, pp. 851-855, 2012.

[8] S. H. Kwon, E. Lee, B.-S. Kim et al., "Activated carbon aerogel as electrode material for coin-type EDLC cell in organic electrolyte," Current Applied Physics, vol. 14, no. 4, pp. 603-607, 2014.

[9] Q. N. K. Nguyen, W. D. Yang, and Z. J. Chung, "Glacial acetic acid catalysed carbon aerogels as electrode material in the electrical double-layer capacitor," Materials Research Innovations, vol. 19, pp. 172-175, 2015.

[10] B. Mathieu, S. Blacher, R. Pirard, J. P. Pirard, B. Sahouli, and F. Brouers, "Freeze-dried resorcinol-formaldehyde gels," Journal of Non-Crystalline Solids, vol. 212, no. 2-3, pp. 250-261, 1997.

[11] T. Horikawa, Y. Ono, J. Hayashi, and K. Muroyama, "Influence of surface-active agents on pore characteristics of the generated spherical resorcinol-formaldehyde based carbon aerogels," Carbon, vol. 42, no. 12-13, pp. 2683-2689, 2004.

[12] H. Tamon, H. Ishizaka, T. Yamamoto, and T. Suzuki, "Freeze drying for preparation of aerogel-like carbon," Drying Technology, vol. 19, no. 2, pp. 313-324, 2001.

[13] N. Job, R. Pirard, J. Marien, and J.-P. Pirard, "Porous carbon xerogels with texture tailored by $\mathrm{pH}$ control during sol-gel process," Carbon, vol. 42, no. 3, pp. 619-628, 2004.

[14] M. A. Aegerter, Aerogels Handbook, Springer, New York, NY, USA, 2011.

[15] R. T. Morrison and R. N. Boyd, Organic Chemistry, PrenticeHall, Upper Saddle River, NJ, USA, 6th edition, 1992.

[16] R. W. Pekala, J. C. Farmer, C. T. Alviso et al., "Carbon aerogels for electrochemical applications," Journal of Non-Crystalline Solids, vol. 225, no. 1-3, pp. 74-80, 1998.

[17] Z. Zapata-Benabithe, F. Carrasco-Marín, and C. MorenoCastilla, "Preparation, surface characteristics, and electrochemical double-layer capacitance of $\mathrm{KOH}$-activated carbon aerogels and their O- and N-doped derivatives," Journal of Power Sources, vol. 219, pp. 80-88, 2012.

[18] S. Mitani, S.-I. Lee, K. Saito, Y. Korai, and I. Mochida, "Contrast structure and EDLC performances of activated spherical carbons with medium and large surface areas," Electrochimica Acta, vol. 51, no. 25, pp. 5487-5493, 2006.

[19] E. G. Calvo, J. A. Menendez, and A. Arenillas, Designing Nanostructured Carbon Xerogels, Nanomaterials, InTech, Rijeka, Croatia, 2011.

[20] R. Brandt, R. Petricevic, H. Pröbstle, and J. Fricke, "Acetic acid catalyzed carbon aerogels," Journal of Porous Materials, vol. 10, no. 3, pp. 171-178, 2003. 

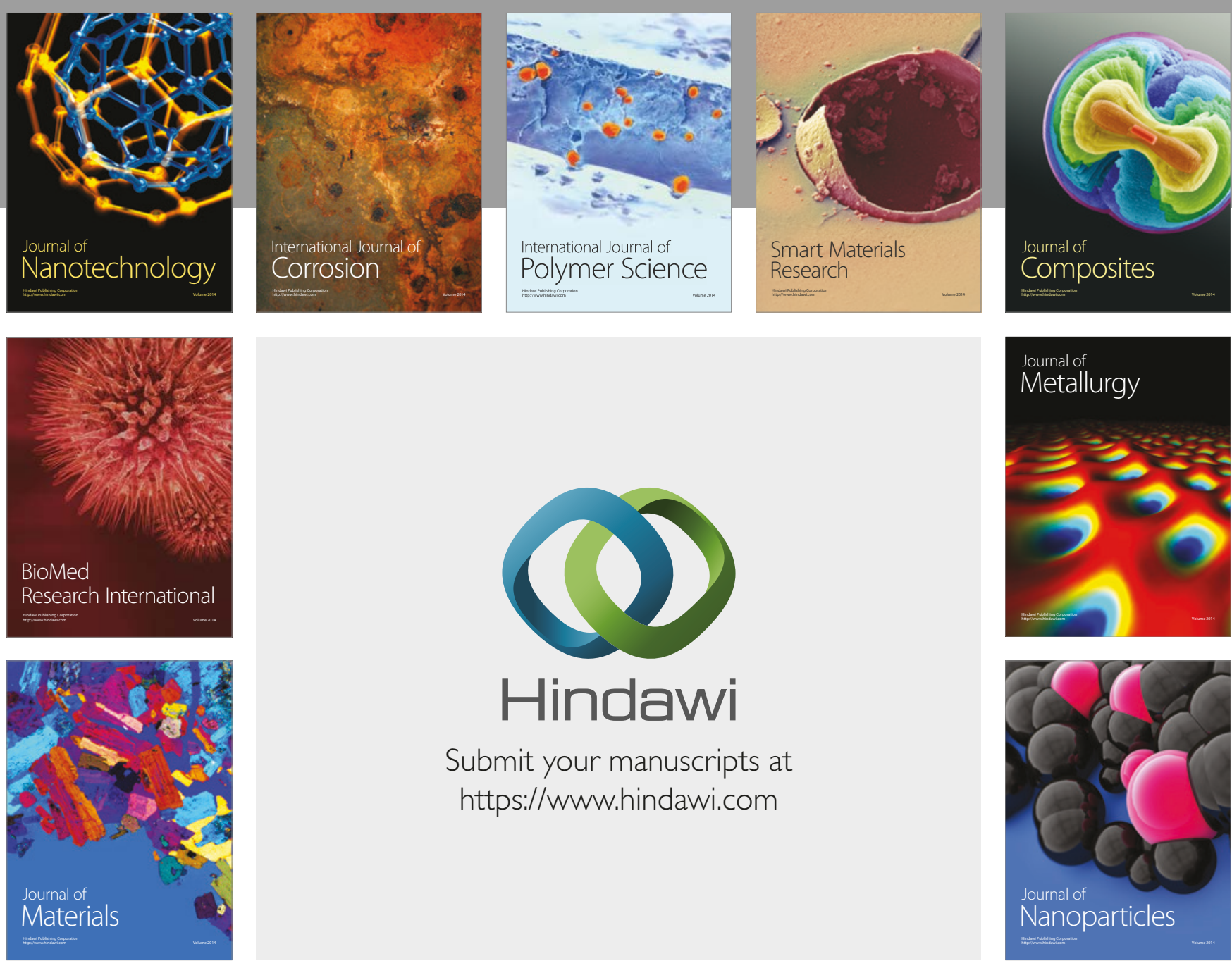

\section{Hindawi}

Submit your manuscripts at

https://www.hindawi.com
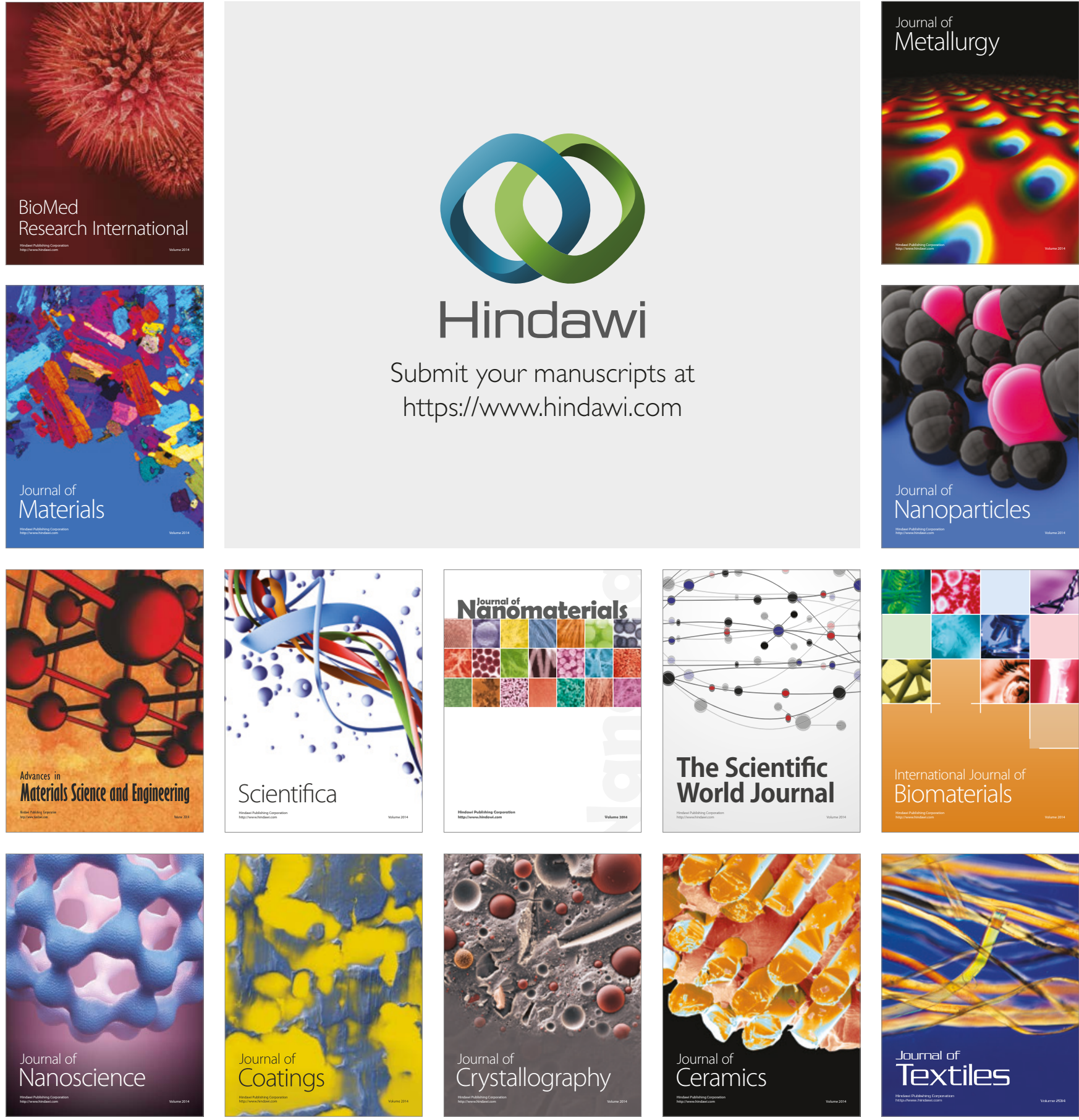

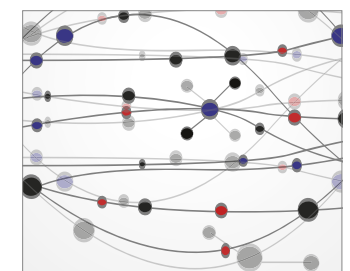

The Scientific World Journal
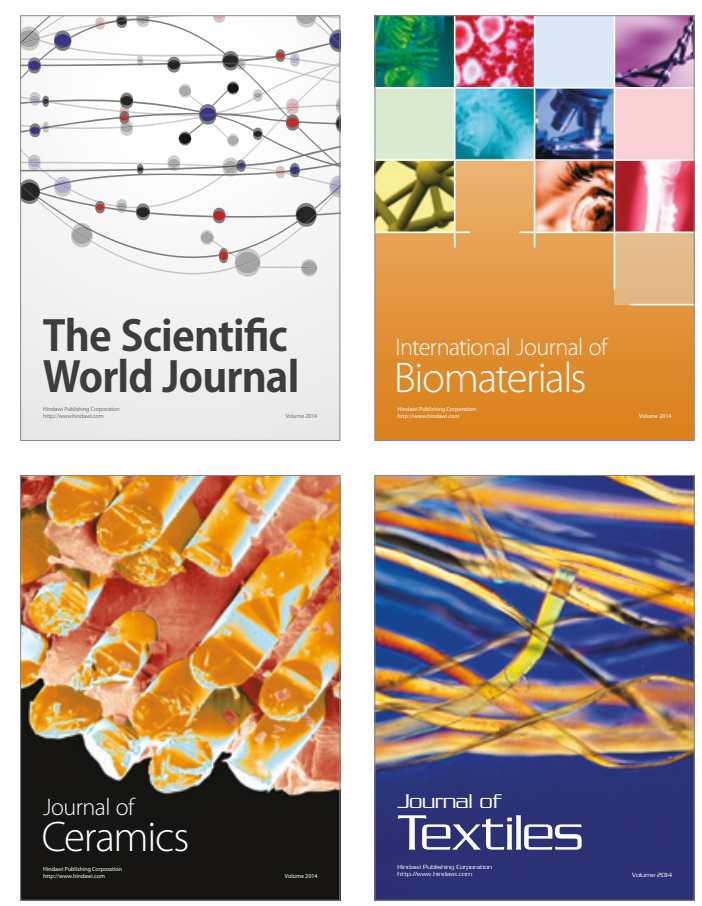